\title{
Study for Determination of the Fitness Level of the Students by Using the Eurofit Battery Tests
}

\author{
Leuciuc Florin Valentin ${ }^{1 *}$ \\ Pricop Gheorghe 2 \\ ${ }^{1}$ Ștefan cel Mare University of Suceava, Universității, 13, 720229, Romania \\ ${ }^{2}$ The Interdisciplinary Research Center for Human Motricity and Health Sciences, \\ Suceava, Universității 13, 720229, Romania
}

Keywords: fitness, students, study

\begin{abstract}
A good fitness level provides individual ability to perform daily tasks and reduce the incidence of certain diseases. The research hypothesis was that curricular and extracurricular activities of students performing various physical activities influence the fitness level of the subjects. The study involved 27 students from the study program Physical Education and Sport (2nd year) of the Faculty of Physical Education and Sport, Stefan cel Mare University of Suceava. It should be noted that their academic activities included 9 hours of practical activities per week, and some of the participants are practicing various sports at performance level, which means between 6 and 10 additional hours of training weekly. In light of these results should be performed an weekly physical activity program, which includes exercise sessions to maintain strength and speed indices of the subjects, and exercises to help develop strength and mobility.
\end{abstract}

\section{Introduction}

Fitness is defined as a set of exercises for physical education practiced to achieve good physical form or condition of a sportsman physically and its preparation (Academia Română, 2009, p. 218, 397). Fitness for health aims to ensure the individual's ability to perform daily tasks and reduce the incidence of certain diseases. Fitness health components are: aerobic endurance, local muscular resistance, muscular strength and power, flexibility, body composition, mental health (Kirk, Cooke, Flintoff, \& McKenna, 2008, p. 63-65). The regular physical activity influence the indicators of growth and maturation, health status, physical fitness, and training for sport (Malina, Bouchard, \& Bar-Or, 2004, p. 392).

The higher physical fitness and leisure-time activity for physical body at young men indicates promotes certain dimensions of health-related quality of life (Häkkinen et al., 2010, p. 15). Another study reveals that the physical activity

\footnotetext{
*E-mail: florinl@usv.ro, tel. +40746972974
} 
levels of both genders decline as they move through adolescence and youth because the moderate or vigorous physical activity are not part of the lifestyle of most European childrens and youngers (Armstrong \& Welsman, 2006, p. 1067-1086).

\section{Material and methods}

The research hypothesis was that curricular and extra-curricular activities of students performing various physical activities influence the fitness level of the subjects. The study involved 27 students from the study program Physical Education and Sport (2nd year) of the Faculty of Physical Education and Sport, Stefan cel Mare University of Suceava. It should be noted that their academic activities included 9 hours of practical activities per week, and some of the participants are practicing various sports at performance level, which means between 6 and 10 additional hours of training weekly. The control tests were applied: standing long jump, keep hanging, trunk lifting, mobility, plate tapping test. The research was conducted during March - June 2015.

\section{Results and Discussions}

After applying the the tests, the data was centralized and was performed mathematical statistics by calculating the following parameters: arithmetic mean, maximum, minimum, standard deviation, coefficient of variation for both initial and final testings (Table 1).

Table 1. Tests results

\begin{tabular}{lcccccccccc}
\hline $\begin{array}{c}\text { The } \\
\text { statistical } \\
\text { parameters } \\
\text { / Tests }\end{array}$ & $\begin{array}{c}\text { Standing long } \\
\text { jump } \\
\text { (cm) }\end{array}$ & $\begin{array}{c}\text { Keep } \\
\text { hanging (s) }\end{array}$ & $\begin{array}{c}\text { Trunk lifting } \\
\text { (no. rep.) }\end{array}$ & $\begin{array}{c}\text { Mobility } \\
\text { (cm) }\end{array}$ & $\begin{array}{c}\text { Plate tapping } \\
\text { test } \\
\text { (s) }\end{array}$ \\
\cline { 2 - 11 } & IT & FT & IT & FT & IT & FT & IT & FT & IT & FT \\
\hline X & 216,26 & 223,41 & 41,81 & 38,85 & 28,37 & 30,04 & 31,67 & 31,00 & 10,33 & 8,06 \\
Max & 135 & 165 & 8 & 7 & 15 & 20 & 10 & 7 & 6,32 & 6,20 \\
Min & 270 & 280 & 72 & 73 & 42 & 36 & 44 & 44 & 13,91 & 10,9 \\
S & 29,62 & 25,54 & 17,58 & 17,49 & 5,34 & 4,21 & 7,79 & 8,03 & 1,89 & 1,24 \\
CV & 13,70 & 11,43 & 42,04 & 45,02 & 18,81 & 14,02 & 24,60 & 25,91 & 18,28 & 15,33 \\
\hline
\end{tabular}

At the standing long jump the individual values were in the range 135-270 $\mathrm{cm}$, the arithmetic mean of $216.26 \mathrm{~cm}$ as initial testing, ie values between 165 and $280 \mathrm{~cm}$ and an average of $223.41 \mathrm{~cm}$ to final testing. The progress achieved was $7.15 \mathrm{~cm}$ and the coefficient of variation values indicate the average homogeneity group (initial testing - 13.70\%; final testing - 11.43\%) (Table 1, Fig. 1). 


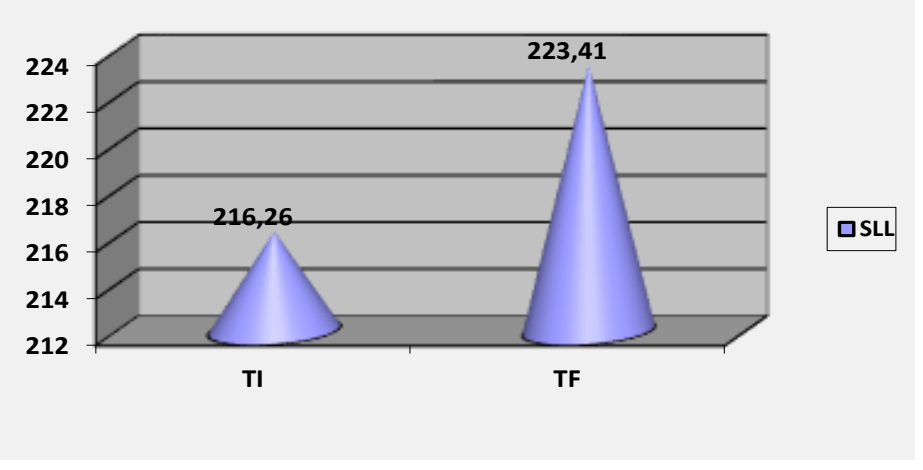

Figure 1. The results for standing long jump

At the keep hanging was declined to 2.96 seconds (initial testing - 41.81 seconds, final testing - 38.85 seconds). The great differences of the individual results (8-72 seconds; 7-73 seconds) made the values for coefficient of variability to be the biggest and small group homogeneity (42.04\%, 45.02\%) (Table 1, Fig. 2).

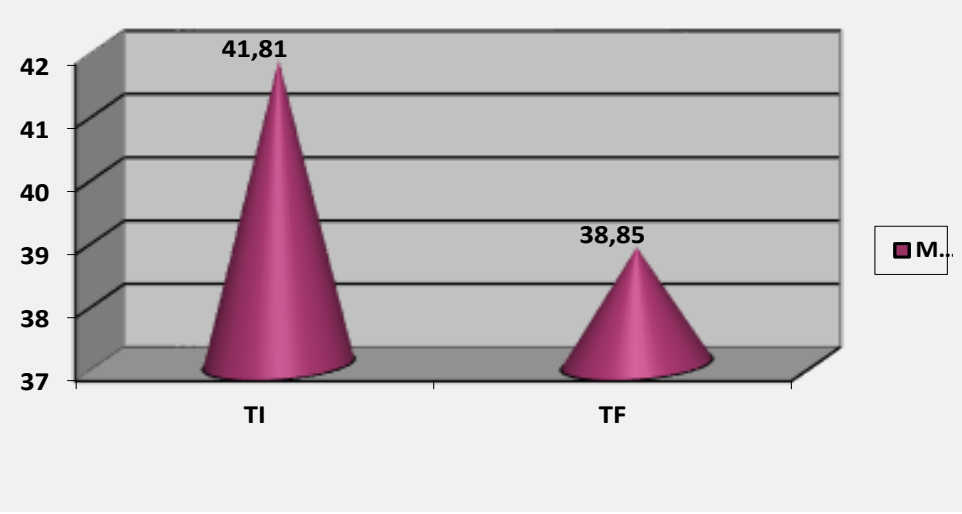

Figure 2. The results for keep hanging

For trunk lifting the individual values were in the range of 15-42 repetitions, the arithmetic mean being 28.37 repetitions at initial testing and values between 30 and 36 repetitions and an average of 30.04 repetitions at the final testing. Progress was 1.67 repetitions and coefficient of variation values indicate the average homogeneity group (initial testing - 18.81\% final testing - 14.02\%) (Table 1, Fig. 3). 


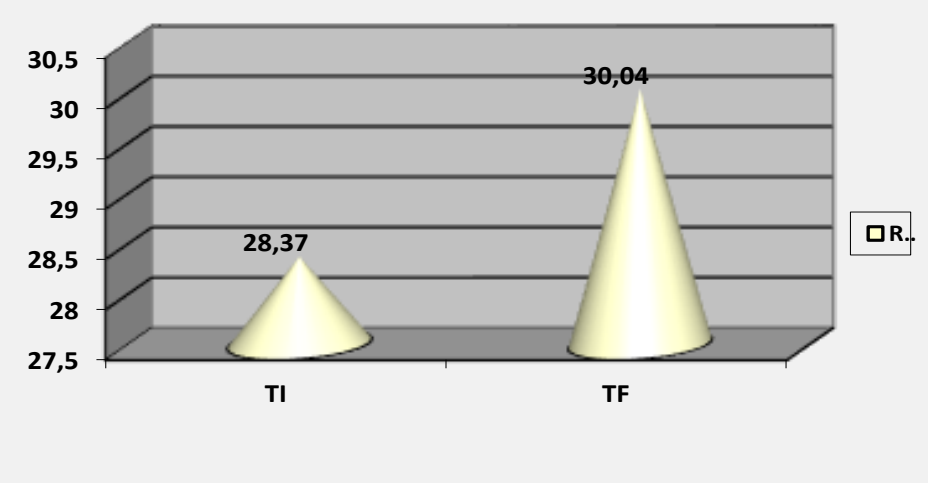

Figure 3. The results for trunk lifting

At the mobility test was a decline by $0.67 \mathrm{~cm}$ (initial testing $-31.67 \mathrm{~cm}$, final testing - $31 \mathrm{~cm})$. The wide variation of individual results $(10-40 \mathrm{~cm}, 7-44 \mathrm{~cm})$ made to a small group homogeneity (24.60\%, 25.61\%) (table 1, figure 4).

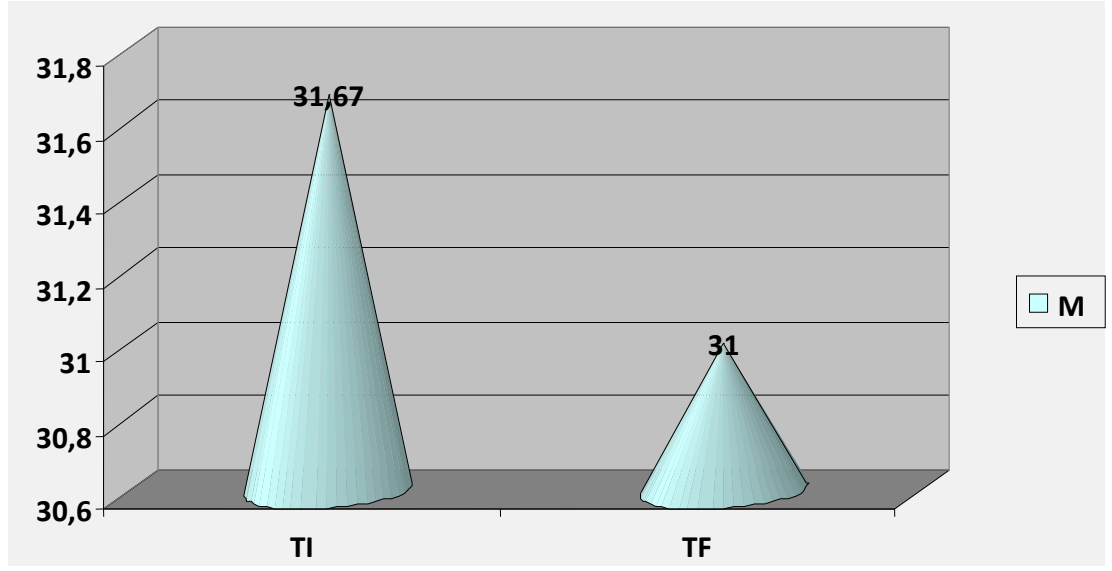

Figure 4. The results for mobility test

At the plate tapping test the individual values were in the range from 6.32 to 13.91 seconds, the arithmetic mean of 10.33 seconds at the initial test and the values between 6.20 and 10.90 seconds and an average of 8.06 seconds at the final testing. Progress was 2.27 seconds and the coefficient of variation values indicate the average homogeneity group (initial testing - 18,28\% final testing - 15.33\%) (Table 1, Fig. 5). 


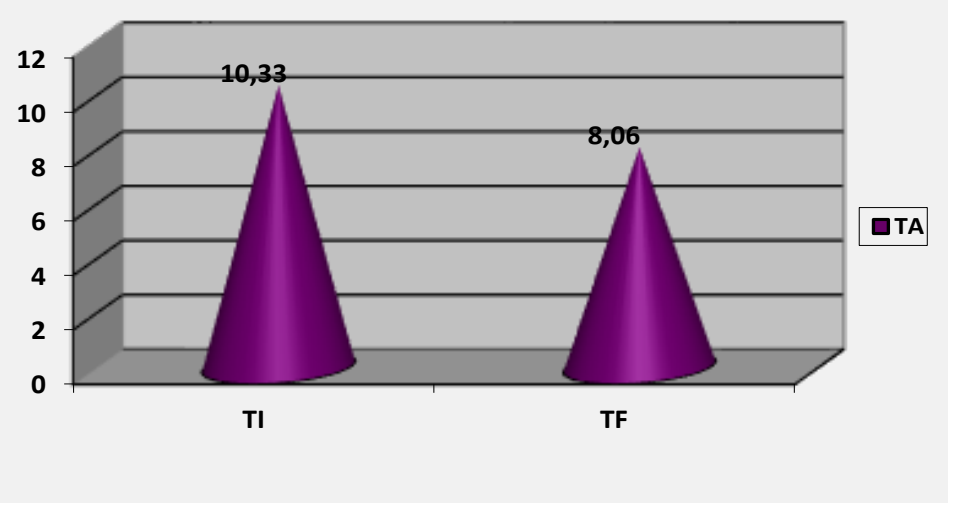

Figure 5. The results for plate tapping test

\section{Discussions}

Similar studies indicate positive effects in young people for body health (Häkkinen et al., 2010, p. 15), but also that not all young people have healthy lifestyle habits regarding exercise practice (Armstrong \& Welsman, 2006, p. 1067-1086).

In light of these results we can say that the research hypothesis is partially confirmed as only certain components of the physical condition have positive effects.

In context of these results and datas from other studies we consider that should be performed an weekly physical activity program, which includes exercise sessions to maintain strength and speed indices of the subjects, and exercises to help develop strength and mobility.

The study limits are on the number of participants (27), but can be a benchmark for other studies aimed the fitness level at youth and students.

\section{Conclusions}

The results indicate some trends in the evolution of the motrical capacity of young people and also provides essential information to establish the workout programs according to their motrical particularities.

There has also been progress at the tests that targeted subjects explosive strenght (standing long jump, trunk lifting), which targeted respectively at speed repetition (plate tapping test). Regress were obtained from two of the five tests: keep hanging (strenght and resistance) and mobility.

\section{References}

1. ACADEMIA ROMÂNĂ, INSTITUTUL DE LINGVISTICĂ "IORGU IORDAN - C.A. ROSETTI". (2009). DEX-Dicţionarul Explicativ al Limbii Române, ediţia a II-a, Bucureşti: Univers Enciclopedic Gold, 218-397; 
2. ARMSTRONG, N., \& WELSMAN, J.R. (2006). The Physical Activity Patterns of European Youth with Reference to Methods of Assessment, Sports Medicine, 36 (12), 1067-1086;

3. HÄKKINEN, A., RINNE, M., VASANKARI, T., SANTTILA, M., HÄKKINEN, K., \& KYRÖLÄINEN, H. (2010). Association of physical fitness with health-related quality of life in Finnish young men, Health and Quality of Life Outcomes, 8, 15;

4. KIRK, D., COOKE, C., FLINTOFF, A., \& MCKENNA, J. (2008). Key concepts in sport \&exercise sciences, London: Sage Publications, 63-65;

5. MALINA, R.M., BOUCHARD, C., \& BAR-OR O. (2004). Growth, Maturation and Physical Activity, Champaign: Human Kinetics, 392.

\title{
Studiu Privind Determinarea Nivelului Condiției Fizice a Studenților Utilizând Teste ale Bateriei Eurofit
}

\author{
Florin Valentin Leuciuc ${ }^{1}$ \\ Gheorghe Pricop ${ }^{2}$ \\ ${ }^{1}$ Universitatea Ștefan cel Mare Suceava, Str. Universității, 13, 720229, Romania \\ ${ }^{2}$ Centrul Interdisciplinar de Cercetare în Științele Motricității și Sănătății Umane \\ Suceava, str. Universității 13, 720229, Romania
}

Cuvinte cheie: condiție fizică, studenți, studiu

\section{Rezumat}

O condiție fizică bună asigură individului capacitatea de a realiza sarcinile cotidiene şi de a reduce astfel incidența anumitor boli. Ipoteza cercetării a fost că activitățile curriculare și extracurriculare ale studenților care practică diverse activități fizice influențează nivelul condiției fizice a subiecților. La studiu au participat 27 de studenți ai programului de studiu Educație Fizică și Sportivă (anul II) din cadrul Facultăţii de Educație Fizică și Sport, Universitatea Ștefan cel Mare din Suceava. Trebuie menționat că în activitatea lor academică sunt incluse 9 ore de activități practice pe săptămână, iar o parte dintre participanți sunt practicanți ai diferitelor discipline sportive la nivel de performanță, ceea ce înseamnă suplimentar între 6 și 10 ore de antrenament săptămânal. În contextul acestor rezultate trebuie efectuate, în programul de activități fizice săptămânal, şedinţe care să cuprindă exerciţ̧i pentru menţinerea indicilor de forţă şi viteză a subiecţilor, precum şi exerciţii care să contribuie la dezvoltarea forţei şi mobilităţii.

\section{Introducere}

Fitness-ul este definit ca un ansamblu de exerciții de educație fizică practicate pentru a obține o bună formă fizică sau ca stare a unui sportiv din punct de vedere fizic și al pregătirii sale (Academia Română, 2009, p. 218, 397).

Fitness-ul pentru sănătate are ca scop asigurarea capacităţii individului de a realiza sarcinile cotidiene şi de a reduce astfel incidenţa anumitor boli. Componentele fitness-ului pentru sănătate sunt: anduranţa aerobă, rezistenţa 
musculară locală, forţa şi puterea musculară, flexibilitatea, compoziţia corporală, sănătatea mentală (Kirk, Cooke, Flintoff, \& McKenna, 2008, p. 63-65). Practicarea regulată a activităților fizice influențează indicatorii de creștere și dezvoltare, starea de sănătate, condiția fizică și pregătirea pentru activitățile sportive (Malina, Bouchard, \& Bar-Or, 2004, p. 392). O condiție fizică foarte bună alături de activități de timp liber dedicate planului fizic la tineri influențeză în mod pozitiv anumite aspecte ale calităţii vieții legate de sănătate (Häkkinen et al., 2010, p. 15). Un alt studiu indică că nivelul activităților fizice pentru ambele sexe scade o dată cu trecerea la adolescență și tinerețe deoarece activitătile fizice moderate și viguroase nu sunt parte a stilului de viață a copiilor și tinerilor europeni (Armstrong \& Welsman, 2006, p. 1067-1086).

\section{Material şi metode}

Ipoteza cercetării a fost că activitățile curriculare și extracurriculare ale studenților care practică diverse activități fizice influențează nivelul condiției fizice a subiectilor.

La studiu au participat 27 de studenți ai programului de studiu Educație Fizică și Sportivă (anul II) din cadrul Facultăţii de Educație Fizică și Sport, Universitatea Ștefan cel Mare din Suceava. Trebuie menționat că în activitatea lor academică sunt incluse 9 ore de activități practice pe săptămână, iar o parte dintre participanți sunt practicanți ai diferitelor discipline sportive la nivel de performanță, ceea ce înseamnă suplimentar între 6 și 10 ore de antrenament săptămânal. Probele de control aplicate au fost: săritură în lungime de pe loc, menținere în atârnat, ridicări de trunchi din culcat, mobilitate, testul de atingeri.

Cercetarea s-a desfășurat în perioada martie - iunie 2015.

\section{Rezultate și discuții}

După aplicarea testelor, datele au fost centralizate și a fost realizată statistica matematică prin calcularea următorilor parametrii: medie aritmetică, valoare maximă, valoare minimă, abatere standard, coeficient de variabilitate atât pentru testarea iniţială cât și pentru cea finală (Tabel 1).

Tabel 1. Rezultate obținute la teste

\begin{tabular}{lcccccccccc}
\hline $\begin{array}{c}\text { Parametrii } \\
\text { statistici } / \\
\text { Teste }\end{array}$ & $\begin{array}{c}\text { Săritură în } \\
\text { lungime de pe } \\
\text { loc } \\
\text { (cm) }\end{array}$ & $\begin{array}{c}\text { Menținere } \\
\text { in atârnat } \\
\text { (s) }\end{array}$ & $\begin{array}{c}\text { Ridicări de } \\
\text { trunchi din } \\
\text { culcat } \\
\text { (nr. rep.) }\end{array}$ & $\begin{array}{c}\text { Mobilitate } \\
\text { (cm) }\end{array}$ & $\begin{array}{c}\text { Testul de } \\
\text { atingeri } \\
\text { (s) }\end{array}$ \\
\cline { 2 - 11 } & TI & TF & TI & TF & TI & TF & TI & TF & TI & TF \\
\hline X & 216,26 & 223,41 & 41,81 & 38,85 & 28,37 & 30,04 & 31,67 & 31,00 & 10,33 & 8,06 \\
Max & 135 & 165 & 8 & 7 & 15 & 20 & 10 & 7 & 6,32 & 6,20 \\
Min & 270 & 280 & 72 & 73 & 42 & 36 & 44 & 44 & 13,91 & 10,9 \\
S & 29,62 & 25,54 & 17,58 & 17,49 & 5,34 & 4,21 & 7,79 & 8,03 & 1,89 & 1,24 \\
CV & 13,70 & 11,43 & 42,04 & 45,02 & 18,81 & 14,02 & 24,60 & 25,91 & 18,28 & 15,33 \\
\hline
\end{tabular}


La săritură în lungime de pe loc valorile individuale au fost în intervalul 135$270 \mathrm{~cm}$, media aritmetică fiind de $216,26 \mathrm{~cm}$ la testarea inițială, respectiv valorile cuprinse între 165 și $280 \mathrm{~cm}$ și o medie de $223,41 \mathrm{~cm}$ la testarea finală. Progresul obținut a fost de $7,15 \mathrm{~cm}$, iar valorile coeficientului de variabilitate indică omogenitate medie a grupei (testarea inițială $-13,70 \%$, testarea finală $-11,43 \%$ ) (Tabel 1, Fig. 1).

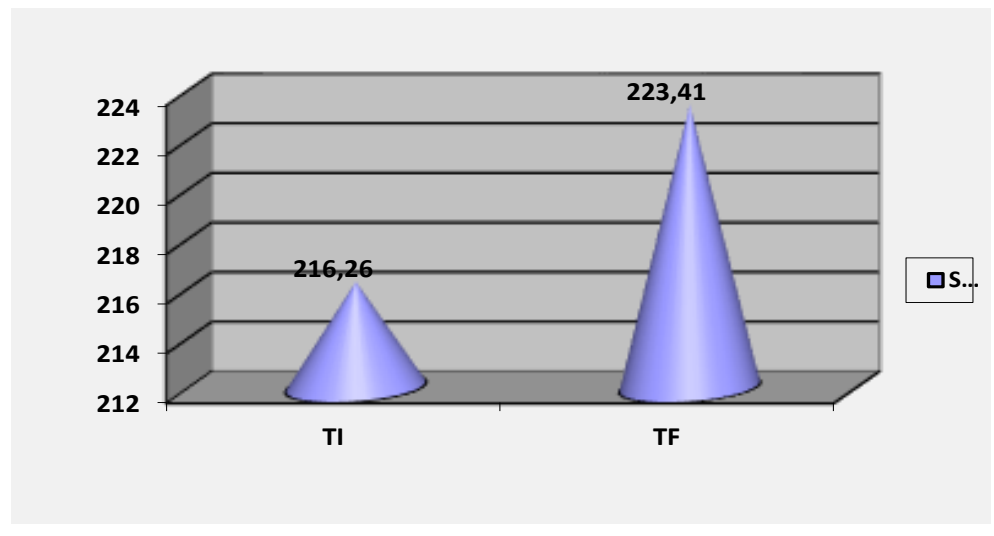

Figura 1. Rezultatele obținute la săritură în lungime de pe loc

La menținere în atârnat s-a înregistrat un regres de 2,96 secunde (testarea iniţială $-41,81$ secunde, testarea finală - 38,85 secunde). Plaja mare a rezultatelor individuale (8-72 secunde, respectiv 7-73 secunde) a făcut ca valorile coeficientului de variabilitate să fie cele mai mari şi să indice omogenitate mică a grupei $(42,04 \%$, 45,02\%) (Tabel 1, Fig. 2).

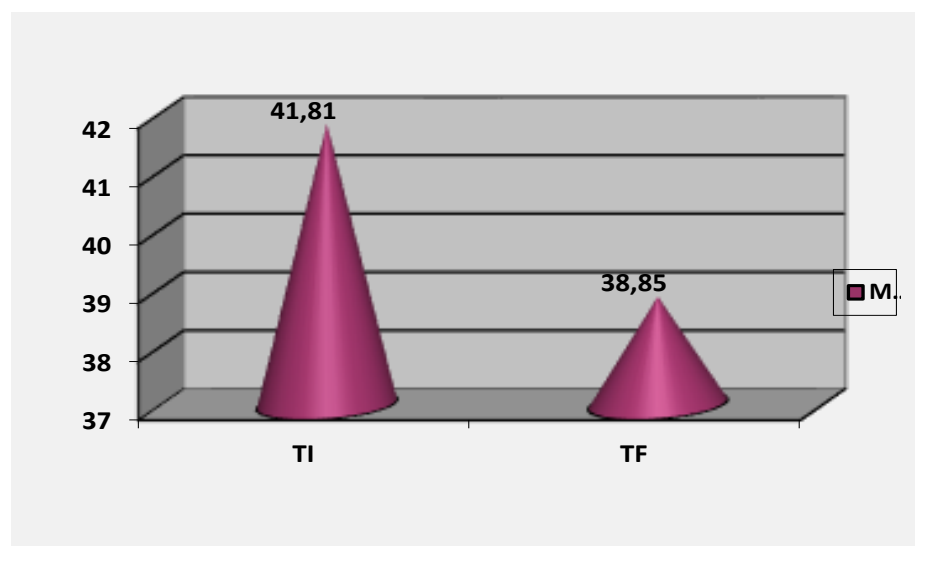

Figura 2. Rezultatele obținute la menținere în atârnat

La proba ridicări de trunchi din culcat valorile individuale au fost în intervalul 15-42 repetări, media aritmetică fiind de 28,37 repetări la testarea inițială şi valorile cuprinse între 30 și 36 repetări și o medie de 30,04 repetări la testarea finală. Progresul înregistrat a fost de 1,67 repetări, iar valorile coeficientului de 
variabilitate indică omogenitate medie a grupei (testarea inițială - 18,81\%, testarea finală $-14,02 \%$ ) (Tabel 1, Fig. 3).

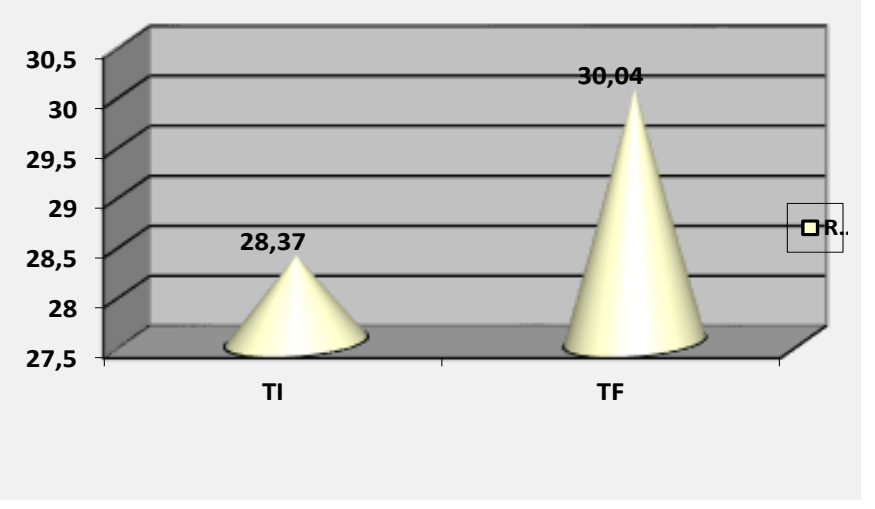

Figura 3. Rezultatele obținute la ridicări de trunchi din culcat

La proba mobilitate s-a înregistrat un regres de $0,67 \mathrm{~cm}$ (testarea iniţială $31,67 \mathrm{~cm}$, testarea finală $-31 \mathrm{~cm})$. Variaţia mare a rezultatelor individuale $(10-40$ cm; 7-44 cm) a făcut ca omogenitate grupei să fie una mică $(24,60 \%, 25,61 \%)$ (Tabel 1, Fig. 4).

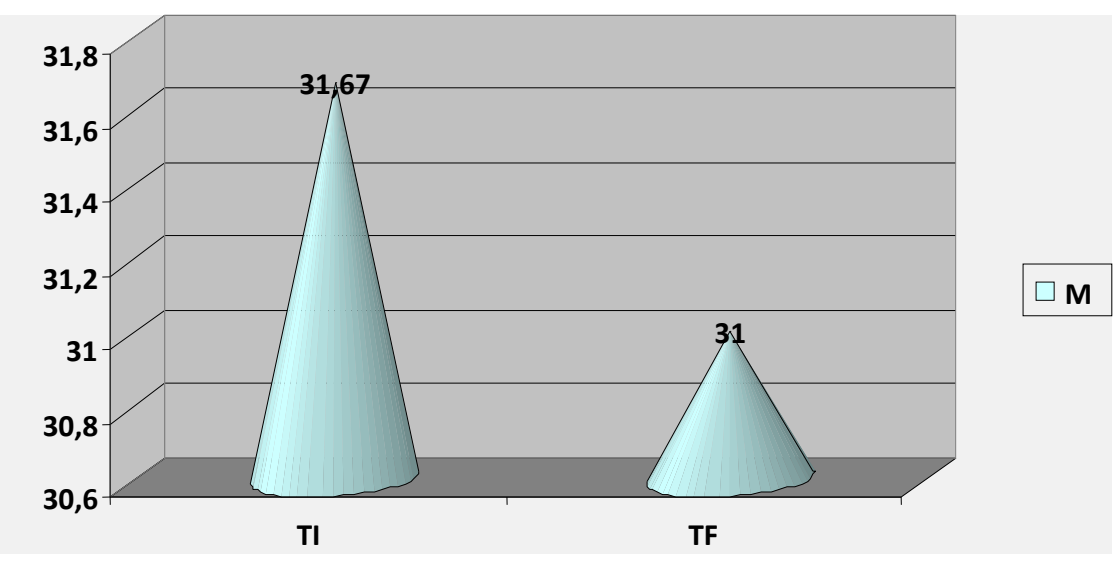

Figura 4. Rezultatele obținute la mobilitate

La testul de atingeri, rezultatele individuale s-au situat în intervalul 6.32 13.91 secunde, media fiind de 10.33 secunde la testarea inițială și valori cuprinse între 6.20 și 10.90 secunde, cu o medie de 8.06 secunde la testarea finală. Progresul a fost de 2.27 secunde și coeficientul de variabilitate a indicat omogenitate medie a grupului (testare inițială - 18,28\%, testare finală - 15,33\%) (Tabel 1, Fig. 5). 


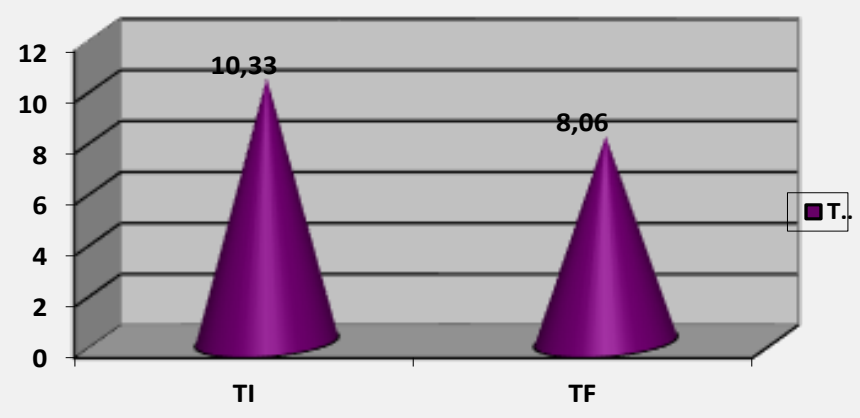

Figura 5. Rezultatele obținute la testul de atingeri

\section{Discuții}

Studii similare efectuate la tineri indică efecte pozitive (Häkkinen et al., 2010, p. 15) în plan fizic și al sănătății, dar și faptul că nu toți tinerii au obiceiuri de viață sănătoase în ceea ce privește practicarea exercițiilor fizice (Armstrong \& Welsman, 2006, p. 1067-1086).

În contextul acestor rezultate și a datelor din literatura de specialitate considerăm că trebuie efectuate, în programul de activităţi fizice săptămânal, şedinţe care să cuprindă exerciţii pentru menţinerea indicilor de forţă şi viteză a subiecţilor, precum şi exerciţii care să contribuie la dezvoltarea forţei şi mobilităţii.

Limitele studiului sunt date de numărul participanților (27), însă se poate constitui într-un reper pentru alte studii care vizează nivelul condiției fizice la tineri și la studenți.

\section{Concluzii}

Rezultatele obţinute indică anumite tendinţe în evoluţia capacităţii motrice a tinerilor şi totodată ne oferă informaţii esenţiale pentru stabilirea unor programe de lucru în concordanţă cu particularităţile motrice ale acestora.

S-au obţinut progrese la probele care au vizat forţa explozivă a subiecţilor (săritură în lungime de pe loc, ridicări de trunchi din culcat), respectiv la cea care a vizat viteza de repetiţie (testul de atingeri). Regrese s-au obţinut la două din cele cinci probe: menţinere în atârnat (forţă în regim de rezistenţă) şi mobilitate.

În lumina acestor rezultate obținute putem spune că ipoteza cercetării este parțial confirmată deoarece numai pe anumite componente ale condiției fizice s-au obținut efecte pozitive. 